\title{
Decision analysis for sustainable systems: making smarter choices for the planet
}

\author{
Raymond R. Tan ${ }^{1}$
}

Published online: 18 July 2016

(c) Springer-Verlag Berlin Heidelberg 2016

Six of the seventeen Sustainable Development Goals (SDGs) recently proposed earlier this year by the United Nations (www.un.org/sustainabledevelopment/sustainabledevelopment-goals/), SDG 6 (Clean Water and Sanitation), SDG 7 (Affordable and Clean Energy), SDG 9 (Industry, Innovation, and Infrastructure), SDG 11 (Sustainable Cities and Communities), SDG 12 (Responsible Consumption and Production), and SDG 13 (Climate Action), arguably fall within the scope of Clean Technologies and Environmental Policy. Since the late 1990s, this journal has consolidated its role as a leading publication that deals with Sustainable Development issues using complementary thrusts of engineering hardware (i.e., Clean Technologies) and soft management interventions (i.e., Environmental Policy). The interface of these two aspects is also a unique feature that presents opportunities for further strengthening this journal's contribution to Sustainability Science.

A few years ago, the paper "A safe operating space for humanity" by Rockström and coworkers appeared in Nature (DOI: 10.1038/461472a). This work proposed quantitative limits or "planetary boundaries" for key environmental issues, namely, climate change, biodiversity loss, biogeochemical cycles, ocean acidification, land use, fresh water use, ozone depletion, atmospheric aerosols, and chemical pollution. The boundaries suggested in the paper take into account both physical planetary limits as well as safety margins to account for uncertainties. A subsequent article by Steffen et al. was then published last year in Science (DOI: 10.1126/science.1259855) that outlined key

Raymond R. Tan

raymond.tan@dlsu.edu.ph

1 De La Salle University, 2401 Taft Avenue, 0922 Manila, Philippines updates on these planetary boundaries. Both these papers highlight how a quantitative analysis of the state of a system (in this case, the entire planet) coupled with a comparison with threshold values can provide valuable insights for decision makers. Even in cases where threshold values are unknown, the analysis reveals data gaps that need to be addressed by researchers. On a similar note, the achievement of the SDGs requires grounding of decisions in a rigorous, quantitative framework. There is plenty of evidence in the scientific literature of strong interest in developing such methods to support decisions. For example, a Scopus search using "sustainability" and "decisionmaking" yields more than 7000 documents; there is also an evident upward trend over the years, culminating in over 900 publications in 2015 .

Since its inception, the journal Clean Technologies and Environmental Policy has established a strong track record in the area of decision analysis in the context of Sustainability Science, most notably through the editor-in-chief's brief but influential paper entitled "On aggregating multiple indicators into a single metric for sustainability" (DOI: 10.1007/s10098-009-0225-4). A Scopus database search using "decision" and "selection" as keywords also yields fifteen articles published in this journal from 2010 to 2015 . Thus, in late 2014, it was agreed to publish a special section to consolidate the journal's place as a venue for publishing work on rational decision support applied to the selection of clean technologies and the development of environmental policies. Two years on, this special section of Clean Technologies and Environmental Policy on the theme of "Decision Analysis for Sustainable Systems" is now being published, and features sixteen articles from contributors based in fourteen different countries. In addition to the core topic of decision analysis, this issue also includes papers utilizing other quantitative techniques, 
such as mathematical programming and pinch analysis, all of which are important tools for providing quantitative decision support for practical decision-making. Furthermore, the scope of applications covered in this issue extends beyond the journal's traditional focus on the process industries, and covers areas such as urban and agroindustrial systems, which are also critical building blocks of human civilization.

The papers in this special section of Clean Technologies and Environmental Policy on "Decision Analysis for Sustainable Systems" comprise a diversified cross section of state-of-the-art scientific work in this area. They represent attempts to rationalize decision-making on increasingly complex sustainability issues using a scientific framework. By comparison, it can be argued that the current state of the environment can be blamed in part on decision-making that has often been ad hoc, short-sighted, or even politically driven. Furthermore, this special section is also envisioned to serve as a catalyst, to stimulate further research and scientific discourse on how we can make smarter choices for the planet. 